\title{
Index Approach to Assessing the Energy Efficiency at a Regional Level
}

\author{
Balashova S.A. Gomonov K.G.*
}

\author{
Peoples' Friendship University of Russia (RUDN University), Economic Faculty, Department of economic and \\ mathematical modelling \\ *Corresponding author. Email: gomonov-kg@rudn.ru
}

\begin{abstract}
The authors propose the Summary Energy Efficiency Index to characterize the efficiency of energy use and energy consumption. The suggested index consists of four pillars: Energy Use, Energy Savings in Public Sector, Smart Consumption, Ecological Footprint. This index enables a comprehensive assessment of energy efficiency mainly on official statistics. Taking into account the structure of end-use electricity consumption in Russia we suggest subdividing regions into four clusters and assessing efficiency of energy use within each cluster. In terms of energy productivity regions with a large share of industry in GRP are rather effective. The level of development of digital technologies in a region is a substantial part of assessing smart energy consumption. However, we should also consider the efficiency of electricity use in the public sector, the development of smart energy and environmental impact, which is essential for sustainable development.
\end{abstract}

Keywords: sustainable development, energy efficiency, electricity consumption, index approach, Russian

regions

\section{INTRODUCTION}

Due to the growing population of the Earth, the issue of providing the population not only with food and water but also with electricity is urgent. Currently, cities consume about $75 \%$ of all energy resources with an urban population of about $53 \%$ of the total. The problem of low energy efficiency, caused by equipment wear, high losses in networks, environmental pollution etc. is still relevant for modern economies. Of course, one can find examples of the active introduction of energy-efficient equipment, advanced technologies, and use of renewable energy sources. The speed of technological changes in the energy sector is so high that what a few years ago seemed like a fantastic future could become a reality over the next ten years.

However, the problem of efficient energy consumption will remain relevant for a long time.

The purpose of this study is to develop a metric for assessing energy efficiency based on the index approach. The index method is commonly used for evaluating the performance of complex systems such as the energy sector. We propose to use not only indicators which are relevant for the current level of development of the electric power industry and energy consumption but include indicators which reflect the prospects of the industry and essential for sustainable development. Taking into account the structure of end-use electricity consumption in Russia we suggest subdividing regions into four clusters and assessing efficiency of energy use within each cluster.

\section{LITERATURE REVIEW}

Modern approaches to assessing the level of energy efficiency are based on the concept of energy efficiency as a system. There is a substantial literature on efficiency indicators and approaches for improving energy efficiency. One of the easy calculate and interpret -the ratio of energy to GDP (EGR) is an indicator often used for the overall economic efficiency of energy use in policy development and analysis. It is tracked and recorded annually in statistical yearbooks of most countries. Numerous studies have also been reported on the relationship between energy consumption and GDP [1, 2, 3, 4]. This approach is well suited for displaying international statistics and benchmarking. Another approach that many countries use is so-called Compound Energy Intensity Index (CEI). Unlike EGR, CEI uses disaggregated energy and activity data to measure energy efficiency using a bottom-up approach. The effect of changes in intensity on energy consumption is achieved by applying an index decomposition analysis (IDA) to each sector using subsector data [1]. Some methods use benchmarks in their approach to calculate the energy efficiency of a region / industry. Thus, it can be built long-term forecasts based on benchmarking information, including in the energy industry [5]. Industrial energy efficiency is of paramount importance both for conserving energy resources and reducing $\mathrm{CO} 2$ emissions is also discussed [6]. Sectoral approaches discuss an integrated way to the index method 
for assessing energy efficiency: Energy Efficiency Index (EEI) as an indicator used to track the performance of energy consumption in buildings [7]. Wider approach is used by calculating a multidimensional SES index. The demand sub-system has been evaluated for four dimensions of SES: Availability, Affordability, Efficiency and (Environmental) Acceptability using 23 selected metrics [8]. Some experts use nonparametric approaches to assessing energy efficiency, for example, market measures for improvement of energy efficiency do not work in the regions with underdeveloped innovation systems. [9]. And its proved that possibility for using a basic input-oriented CCR DEA model for solving the problem of choosing an optimal environmental management strategy for a generating company [10]. The combination of Data Envelopment Analysis and using the index method allows to effectively identify sources of inefficiency, assess the efficiency overtime in each unit and establish quantitative targets for improvement. This method can be applied in a wide range of energy-intensive industrial processes (i.e., chemical, automotive, metallurgy, etc.) to minimize energy losses in the transition to a more sustainable world [11].

Our contribution to the existing literature is as follows. We propose the methodology to evaluate energy efficiency by composite index at a regional level taking onto account energy intensity, the use of energy-saving technologies, smart consumption and ecological footprint.

\section{METHODOLOGY}

\subsection{Basic indicators of Energy Efficiency}

The concept of energy efficiency is quite capacious and includes several components. First, energy efficiency is the rational use of energy resources which is measured by such an indicator as energy intensity. Energy intensity is the specific indicator of energy consumption (electricity) per unit value of the gross product (of a country or a region). Energy consumption is more efficient (in terms of creating gross value added) if the energy intensity is decreasing.

Energy intensity reduction can be achieved by restructuring a region's economy in favour of less energyintensive sectors and using energy-saving technologies in traditional sectors of the economy and non-productive consumption (commercial and residential sectors, transportation).

However, energy efficiency is not identical to energy intensity. This is a more comprehensive concept, which should also reflect the use of energy-saving technologies in the public sector, the reasonable consumption by the population, industry and transport, as well as the impact on the environment.

We propose to assess energy efficiency by the composite energy index consisting of four pillars: Energy Use, Energy Savings in Public Sector, Smart Consumption, Ecological Footprint.

In this section, we discuss the definitions and rationale for the indicators we propose to include in the Summary Energy Efficiency Index (SEEFI) (Table 1).

Table 1 Energy efficiency indicators

\begin{tabular}{|l|l|}
\hline Indicator & Description \\
\hline Energy use & Composite sub-index EEFI_I \\
\hline Energy Intensity of GRP & $\begin{array}{l}\text { Base indicator: the ratio of energy consumption to the gross } \\
\text { regional product in constant prices }\end{array}$ \\
\hline Energy Consumption per Capita & Base indicator: the ratio of energy consumption to population \\
\hline Energy Savings in Public Sector & Composite sub-index EEFI_II \\
\hline Efficient Energy Consumption in Public Buildings & $\begin{array}{l}\text { Base indicator: share of buildings with advanced energy } \\
\text { efficiency class D and above }\end{array}$ \\
\hline Energy Efficient Lighting & $\begin{array}{l}\text { Base indicator: the share of LED light sources in the indoor } \\
\text { and outdoor lighting of the public sector }\end{array}$ \\
\hline Use of Policy Instruments & $\begin{array}{l}\text { Base indicator: The share of the state programs on energy } \\
\text { efficiency in a particular region }\end{array}$ \\
\hline Smart Consumption & Composite sub-index EEFI_III \\
\hline Smart Metering & $\begin{array}{l}\text { Base indicator: the share of installed metering devices with } \\
\text { feedback }\end{array}$ \\
\hline Smart City & Base indicator: share of smart cities in the region \\
\hline ICT Development & $\begin{array}{l}\text { Composite indicator: composite index combined of 10 } \\
\text { indicators divided into 3 groups }\end{array}$ \\
\hline Ecological Footprint & Composite sub-index EEFI_IV \\
\hline Renewable Energy & $\begin{array}{l}\text { Base indicator: the share of renewable energy sources (RES, } \\
\text { including hydropower) \% total production }\end{array}$ \\
\hline CO2 Emission From Fuel Combustion & Base indicator: CO2 emissions from fuel combustion (MtCO2) \\
\hline \multicolumn{1}{|c|}{ Source: compiled by the authors. } &
\end{tabular}


Definitions and discussion of the SEEI indicators

\section{I.1. The inverse ratio of Energy intensity of GRP}

Numerator: Energy consumption (kg of fuel).

Denominator: Gross regional product at constant prices (RUR)

Rationale: The indicator shows the cost of converting energy into GRP. It is measured by the quantity of energy required to perform a regional activity (service), expressed as energy per unit of output.

I.2. The inverse ratio of Energy use per capita

Numerator: Energy consumption (kg of fuel).

Denominator: Population (thousands of people).

Rationale: The indicator shows the huge disparity in energy use primarily reflects different climate conditions and income levels in the RF regions.

\section{II.1. Efficient Energy Consumption in Public Buildings}

Numerator: Buildings with advanced energy efficiency Dclass and more.

Denominator: Total buildings of the public sector.

Rationale: the proportion of buildings with advanced energy efficiency class D and above.

Classification is given according to GOST R 54862-2011:

- Class D - buildings in which there is no need to use building automation and control systems (BACS) to manage the energy efficiency of the building;

- Class C - buildings that use simplified BACS;

- Class B - buildings that use advanced BACS and some specific TBM functions;

- Class A - buildings that use energy-efficient BACS and technical building management (TBM).

\section{II.2 Energy Efficient Lighting}

Numerator: LED light sources in the indoor and outdoor lighting of the public sector.

Denominator: Total light sources in the indoor and outdoor lighting of the public sector.

Rationale: the share of LED light sources in the indoor and outdoor lighting of the public sector.

\section{II.3 Use of Policy Instruments}

Numerator: Energy efficiency programs.

Denominator: Total development programs.

Rationale: The share of the programs of a region, aiming at energy efficiency, is an indicator of consolidated efforts at a public level.

III.1. Smart Metering
Numerator: The number of smart metering devices that allow the consumer to track usage in real-time.

Denominator: Total quantity of energy consumers.

Rationale: Many experts and researchers report a decline in electricity consumption while using smart metering [12].

\section{III.2. Smart City}

Numerator: Quantity of smart cities.

Denominator: Total quantity of big cities in a region.

Rationale: The share of smart cities in a region shows a level of development of new technologies [13].

\section{III.3 ICT Development}

The ICT Development is a composite index combining ten indicators into one benchmark measure that can be used to monitor and compare developments in information and communication technology (ICT) between regions of the country. The ICT Development is divided into three subindices: the access sub-index, the use sub-index and the skills sub-index, which capture different aspects of the ICT development process. The methodology is based on International Telecommunication Union research [14].

Rationale: The implementation of the Smart Grid relies heavily on information and communication technologies (ICT), however, interregional differences in the development of ICT infrastructure in the RF hamper the widespread introduction of Smart Grid elements [15].

\section{IV.1. Renewable Energy}

Numerator: Energy production from renewable energy sources (RES, including hydropower).

Denominator: Total energy production.

Rationale: Although it is forecasted that thermal power plants will account up to $60 \%$ of the global electric power production, the share of renewable energy sources can reflect the efficiency of power grids because it helps to reduce losses and increase productivity [16].

\section{IV.2 CO2 Emission}

Numerator: $\mathrm{CO} 2$ emissions from fuel combustion in a region

Denominator: $\mathrm{CO} 2$ emissions from fuel combustion in the $\mathrm{RF}$

Rationale: $\mathrm{CO} 2$ emissions are anthropogenic emissions from the combustion of fossil fuels. This indicator at the macro-level is calculated by IEA (CO2 emissions from fuel combustion, 2017) and considered to be important with policy considerations are increasingly driven by concerns about environmental sustainability, economic competitiveness, energy security, air pollution, and climate change. By order of the Ministry of Natural Resources of Russia, the subjects of the Russian Federation must provide information on greenhouse gas emissions, 
measures to reduce them and a voluntary inventory of emissions since 2017.

\subsection{Technical Details}

To calculate SEEFI we follow the methodology of the EU Innovation Index (Innovation Union Scoreboard 2011, 2012). The methodology needs an algebraic transformation of the indicators' raw values that is useful for preparing the indicators to the subsequent weighting/aggregation. In particular, we use a standard min-max normalization to build each pillar EEFI as a weighted sum of re-scaled indicators.

If an indicator's growth is interpreted as an increase in energy efficiency, then the normalized indicator is associated with an integral monotonically increasing dependence. This consists in subtracting the lowest indicator value found in the group of regions over several years $Z_{i, \min }$ and then dividing by the difference between the highest $\mathrm{m}_{i, \max }$ and the lowest $Z_{i, \text { min }}$ values found within the same group of observations:

$$
X_{i k}=\frac{Z_{i k}-Z_{i, \min }}{Z_{i, \max }-Z_{i, \min }}
$$

If there is an opposite relationship between a raw indicator and energy efficiency, the relationship is

$$
X_{i k}=\frac{Z_{i \max }-Z_{i, k}}{Z_{i, \max }-Z_{i, \min }}
$$

The maximum re-scaled score is equal to 1 and the minimum value is equal to 0 .

Summary Energy Efficiency Index SEEFI is calculated as linear aggregation with weights of the scores for the four pillars: Energy use EEFI_I, Energy Savings in Public Sector EEFI_II, Smart Consumption EEFI_III and Ecological Footprint EEFI_IV. This is the simplest technique which implies full compensability of the scores (low performance in some indicators can be traded with high performance in others). Setting aside the problem of weights selection, the composite indicator for a region $\mathrm{k}$ at time $t$ is the sum of the component indicators weighted by the coefficients $\mathrm{w}_{\mathrm{i}}$,

SEEFI $=\sum_{i=1}^{m} w_{i}$ EEFI $_{i}$

which are selected such that $\sum w_{i}=1$

The indicators within each pillar are aggregated linearly with equal weights to simplify the approach.

Note, that using min-max normalization the overall minimum and/or maximum must be updated and the whole SEEFI to be recalculated across the past years. In this way, the composite index maintains comparability across time, yet the past values of the SEEFI could have changed.

\section{RESULTS AND DISCUSSION}

In this paper, we show the results of assessing the efficiency of energy use by the Russian regions (the first part of the composite index SEEFI). We retrieve data from Rosstat (FSSS).

Electricity consumption structure in Russia differs from that in USA and most European countries where transportation and residential sector are main consumers. In Russia the industrial sector is the most electricityintensive sectors and accounted for 53\% of total electricity consumption in the RF in 2015 (Fig.1). The variance in electricity demand within the industrial sector is substantial as Textile and leather production is less intensive than Iron and steel. Thus, the industrial sector energy consumption varies by region, due to differences in gross industrial output, energy intensity (measured as energy consumed per unit of gross output), and the GRP structure.

The regions of the Russian Federation vary considerably in terms of economic development and socio-economic indicators. To evaluate the composite sub-index EEFI_I, we first carry out a typology of the regions based on population and industry share in GRP. We plot the relationship between population, industrial share of GDP and energy consumption in the diagram (Fig.2).

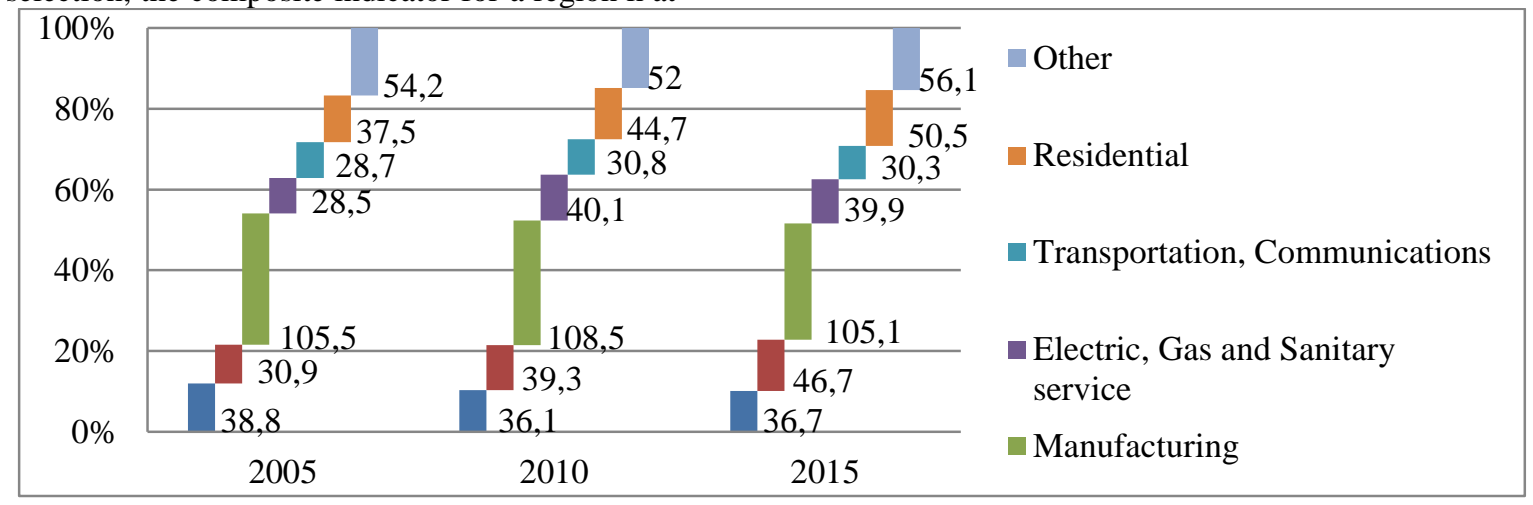


Figure 1. Structure of electricity consumption in RF, 2005-2015

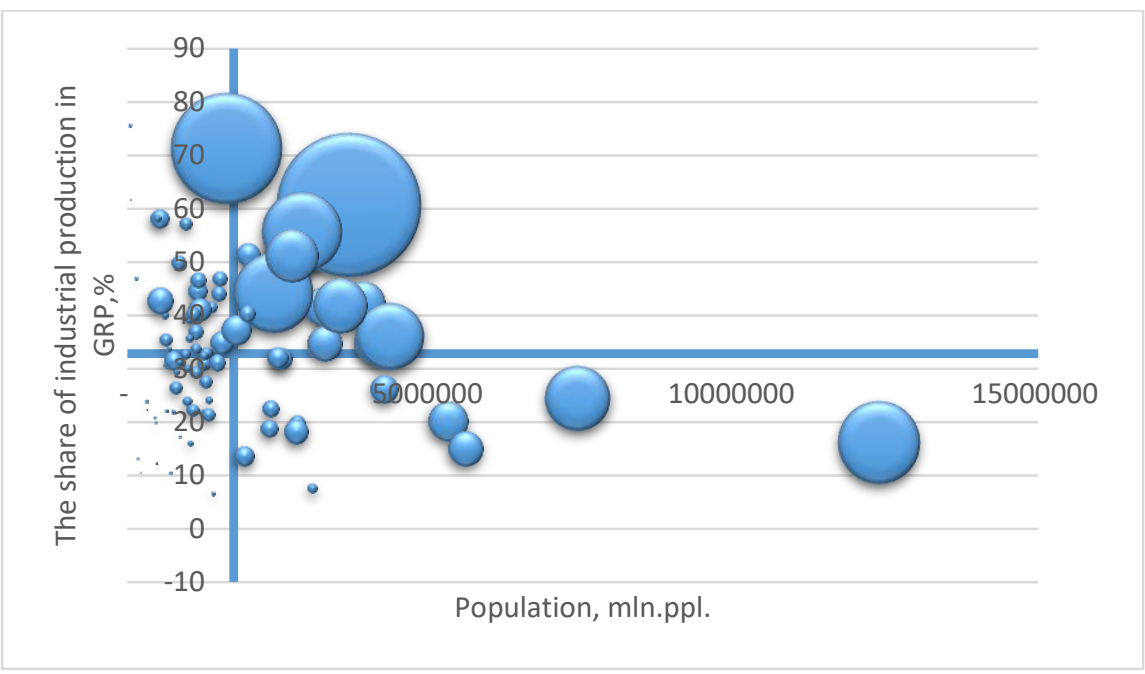

Figure 2 Scatter-plot on the share of industrial production vs. population with the indication of energy consumption in the regions of the Russian Federation in 2016

The blue lines are the median share of industry in GRP, which is $32 \%$, and the median of the population, which is 1184 thousand. The size of the bubble in the diagram shows the energy consumption level of the region. Fig. 2 shows that there are regions with a large population and relatively low energy consumption and intensively energyconsuming regions with a relatively small population in Russia. We subdivide all regions for four clusters using industry share and population as criteria.

We apply the formula (2) to calculate the normalized score of the two indicators from Table 1 for Energy use index
EEFI_I as the relationship between energy efficiency and energy intensity of GDP and electricity consumption per capita is negative. We calculate the normalized score within each cluster, taking into account the GRP structure and the size of a region in terms of population.

We utilize the described methodology to calculate subindex EEFI_I for each cluster.

Clusters of regions of the Russian Federation depending on the sectoral structure of GRP, population and electricity consumption we display in Table 2 .

Table 2 Clusters of regions

\begin{tabular}{|c|c|c|c|c|c|c|}
\hline Clusters & Population & $\begin{array}{l}\text { Industry share in } \\
\text { GRP }\end{array}$ & $\begin{array}{l}\text { Number of } \\
\text { regions } \\
2016\end{array}$ & $\begin{array}{l}\text { Normalized } \\
\text { score of } \\
\text { Energy } \\
\text { Intensity } \\
\text { Median }\end{array}$ & $\begin{array}{l}\text { Normalized } \\
\text { score of } \\
\text { Electricity } \\
\text { consumption } \\
\text { Median }\end{array}$ & $\begin{array}{l}\text { Normalized } \\
\text { score of } \\
\text { EEFI_i } \\
\text { Median }\end{array}$ \\
\hline 1 & Less than median & More than median & 19 & 0.89 & 0.74 & 0.78 \\
\hline 2 & $\begin{array}{l}\text { More than } \\
\text { median }\end{array}$ & More than median & 21 & 0.91 & 0.78 & 0.81 \\
\hline 3 & $\begin{array}{l}\text { More than } \\
\text { median }\end{array}$ & Less than median & 19 & 0.46 & 0.66 & 0.52 \\
\hline 4 & Less than median & Less than median & 24 & 0.6 & 0.53 & 0.54 \\
\hline
\end{tabular}

Source: compiled by the authors. 
As we can see from Table 2, regions with large population and a relative small share of industry in GRP are not so efficient in terms of energy use.

Note that for regions from the second cluster the issue of energy efficiency is very important as they have the highest energy consumption as shown in Figure 2.
The Pareto chart of the EEFI_I for regions in the second cluster is plotted in Fig.3.

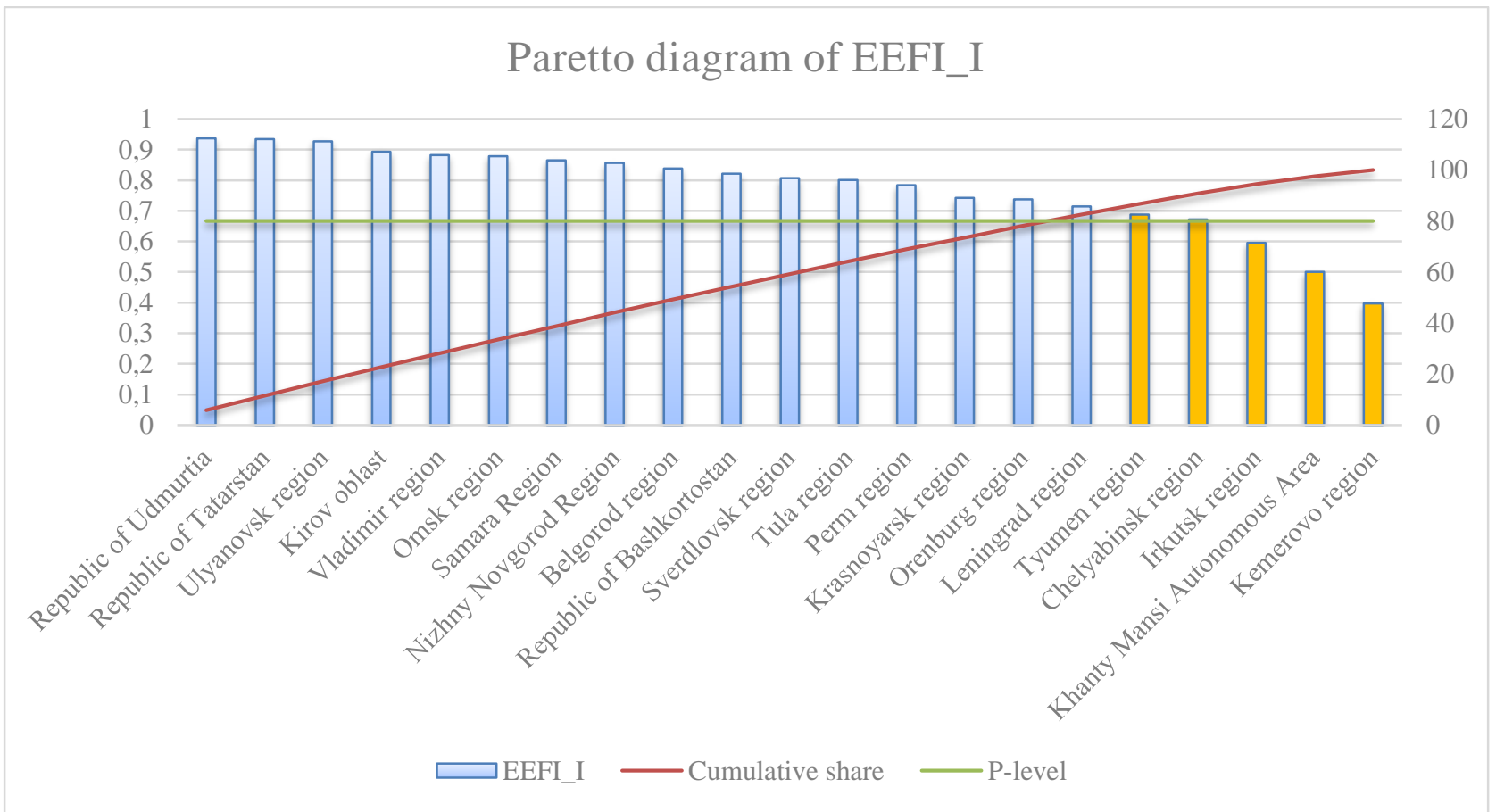

Figure 3 Pareto chart of the EEFI_I

We can see that most part of the regions in this cluster are energy efficient in terms of energy use, taking into account a rather large population and large industry share in GRP. Moreover, less energy-efficient regions mostly locate in adverse climatic zones, which also should be taken into account.

\section{CONCLUSION}

The modern strategy of energy developing is to ensure sustainable economic growth and transformation of the economy in favour of less energy-intensive industries, to improve the quality of life. It is based on energy security, the energy efficiency of the economy, the economic efficiency of energy and environmental safety, etc. The achievements in this way can be assessed with the use of the proposed Summary Energy Efficiency Index.

Available information dataset enables us to calculate only the first pillar of the composite index. Next steps are to figure other sub-indexes using the proposed methodology and build the comprehensive picture of energy efficiency taking into account not only energy consumption itself but also the development of smart energy system and the environmental impact.
However, to assess the energy efficiency in general, we need to consider how the residential and the public sector use saving technologies and what are ecological consequences of energy use.

\section{ACKNOWLEDGMENT}

This work was supported by the Economic Faculty of the People's Friendship University of Russia (RUDN University).

\section{REFERENCES}

[1] Ang, B., \& Goh, T. (2018). Bridging the gap between energy-to-GDP ratio and composite 
Applications, $\quad$ 17(4), 78-92. https://doi.org/10.25728/assa.2017.17.4.521

[11]Fernández, D., Pozo, C., Folgado, R., Jiménez, L., \& Guillén-Gosálbez, G. (2018). Productivity and energy efficiency assessment of existing industrial gases facilities via data envelopment analysis and the Malmquist index. Applied Energy, 212, 15631577. https://doi.org/10.1016/j.apenergy.2017.12.008.

[12] TAdviser.ru. (2020). 5G: in detail about technologies and perspectives of new generation networks.. [online] Available at: http://tadviser.com/index.php/Article:5G_\%28fifth _generation_of_mobile_communication $\% 29$ [Accessed 5 Jan. 2020].

[13] Boykova, M., Ilina, I., \& Salazkin, M. (2016). The Smart City Approach as a Response to Emerging Challenges for Urban Development. Foresight And STI Governance, 10(3), 65-75 https://doi.org/10.17323/1995-459x.2016.3.65.75

[14]Measuring the Information Society (2015). Available at: https://www.itu.int/en/ITUD/Statistics/Documents/publications/misr2015/MIS R2015-ES-E.pdf. [Accessed 5 Jan. 2020].

[15] Revinova, S., Balashova, S. and Lazanyuk, I. (2015) 'ICT in Russia: the Current State, Government Support, and Main Trends', International Journal of Business and Management Studies, 04(02), pp. 127-143.

[16] Matyushok, V., Balashova, S., \& Gomonov, K. (2019). Electricity consumption for the Russian economy: does smart grid matter. International Journal Of Economic Policy In Emerging Economies, $12(4), \quad 407$. https://doi.org/10.1504/ijepee.2019.104630

[8] Narula, K., Sudhakara Reddy, B., \& Pachauri, S. (2017). Sustainable Energy Security for India: An assessment of energy demand sub-system. Applied Energy, 186, 126-139. https://doi.org/10.1016/j.apenergy.2016.02.142

[9] Ratner, S., \& Ratner, P. (2016). Regional Energy Efficiency Programs in Russia: The Factors of Success. $\quad$ REGION, 3(1), 69. https://doi.org/10.18335/region.v3i1.71

[10] Ratner, S., \& Ratner, P. (2017). Developing a Strategy of Environmental Management for Electric Generating Companies Using DEAMethodology. Advances in Systems Science and 